\title{
Rafael Altamira, Proceso histórico de la Historiografía humana. México: El Colegio de México, 1948 (2ª ed., 2011), 208 págs.
}

El libro que a continuación presentamos reúne las lecciones de historia de la historiografía que Rafael Altamira (Alicante, 1844-Ciudad de México, 1951) impartió a los alumnos de El Colegio de México durante 1946. Dos años antes, Rafael Altamira había arribado a México junto con su familia después de haber emprendido la penosa senda del exilio por Francia, Portugal y Nueva York. Con casi ochenta años de vida, don Rafael regresaba a tierras mexicanas sin el entusiasmo con el que treinta y cuatro años antes, como representante de la Universidad de Oviedo, había recorrido el Distrito Federal, Veracruz y Yucatán, para proponer una serie de iniciativas encaminadas a establecer un intercambio de recursos universitarios tanto humanos como bibliográficos, acuerdos científicos, comerciales y migratorios. Esta vez el jurista, ex juez de la Corte Internacional de La Haya, el historiador comprometido con una historiografía en aras de la paz, llegaba "maltratado espiritual y físicamente" por los acontecimientos bélicos iniciados en su país y que alcanzando la escala "mundial” aún continuaban. No obstante, don Rafael Altamira sacó fuerzas en tierras mexicanas, "renovó sus bríos, volvió a sus clases y conferencias (...) y se puso con renovadas ansias e incluso furia a investigar y escribir". ${ }^{1}$

En efecto, aunque no tenía consigo todos sus materiales pues la guerra iniciada en 1936 se los había arrebatado, en México Altamira revisó bibliografía, trabajó en nuevas ediciones de sus libros con sus respectivas correcciones y actualizaciones y preparó cursos para seguir formando a otra más de tantas generaciones. Como diría uno de sus discípulos, Javier Malagón: "México supo captarse a don Rafael y él, por su parte, entregase de todo corazón a esta tierra generosa con aquellos que en su idea de vida ponen por encima de todo la libertad del hombre y de los pueblos". ${ }^{2}$ Otro de sus discípulos y antiguo tesista, Silvio Zavala, lo acogió en el Centro de Estudios Históricos de El Colegio de México, institución de educación superior fundada en 1940 cuyo antecedente inmediato fue La Casa de España (1938-1940), la cual, entre otras cosas, se encargó de recibir y abrir espacios a los exiliados españoles en las diversas instituciones educativas y culturales mexicanas. Zavala, quien había regresado de la capital española en 1937, fundó el Centro de Estudios Históricos en 1941, con el propósito de cultivar la historia de México y de Hispanoamérica y con la visión de que la "aportación del nuevo historiador debía basarse en la investigación, en la elaboración de materiales nuevos que por necesidad debía espigar en los archivos, en la interpretación exacta y cuidadosa de las fuentes”. ${ }^{3}$

\footnotetext{
${ }^{1}$ Juan Ortega y Medina, “Historia”, en Francisco Martínez de la Vega y otros, El exilio español en México 1939-1982 (México: Salvat-Fondo de Cultura Económica, 1982), 260, 261.

${ }^{2}$ Javier Malagón y Silvio Zavala, Rafael Altamira y Crevea: el historiador y el hombre (México: Universidad Nacional Autónoma de México-Instituto de Investigaciones Históricas, 1971), 72.

${ }^{3}$ Clara E. Lida y José Antonio Matesanz, La Casa de España y El Colegio de México: memoria 1938-2000 (México: El Colegio de México, 2000), 180.
} 
Los cursos del Centro se completaron con asignaturas sobre historia de España y otras más generales como historia de la cultura, del arte y de la literatura. La segunda promoción de alumnos se benefició con la programación de cursos metodológicos, formativos generales y particulares. En este contexto, a Rafael Altamira se le encargó un curso sobre "Orientaciones para el estudio de la Historia”. Además, la Facultad de Filosofía y Letras y la Escuela Nacional de Jurisprudencia de la Universidad Nacional Autónoma de México invitaron al profesor Altamira a impartir algunas asignaturas y conferencias. En la Facultad de Filosofía enseñaría "Historia de la civilización española” durante 1945, mientras que en la Escuela Nacional de Jurisprudencia dictaría algunas conferencias sobre la historia del derecho español en $1947 .{ }^{4}$

Precisamente, sobre el tema de la historia de la civilización, Rafael Altamira centró sus esfuerzos en dictar entre junio y diciembre 1946, en el Centro de Estudios Históricos de El Colegio de México, el curso "Preparación para la técnica de la Historiografía humana". La propuesta inicial de este curso estaba dirigida a un grupo numeroso y conformado en su mayoría por estudiantes extranjeros, pero tuvo que modificarse a causa de una enfermedad padecida por Altamira. El nuevo contenido se pensó para un número menor de alumnos matriculados y se propuso como objetivo general "comprender cómo las generaciones de muchos siglos (...) han podido legar una posición sólida en cuanto a la manera de concebir y de exponer la historia de la humanidad y de cada uno de los pueblos antiguos y modernos". ${ }^{5}$ Asimismo, se planteó como objetivo específico que los alumnos conocieran "el proceso que durante siglos fue trazando la curva conceptual de la Historia como forma de literatura que busca el relato y la explicación de las actividades humanas creadoras del hecho antropológico de la vida social”. ${ }^{6}$

Para conseguir estos objetivos el curso se programó en tres secciones. La primera estaba dirigida a enseñar la "doctrina metodológica”. En la segunda parte se expondría "el proceso de formación del concepto histórico" y las "posiciones de los historiógrafos a través del tiempo". La tercera sección estaba destinada a presentar una "bibliografía escogida”. Don Rafael concedería más importancia a la segunda sección y apoyaría sus lecciones en sus obras: La enseñanza de la historia y Cuestiones modernas de historia, ambas en sus segundas ediciones (1895 y 1935); De Historia y Arte (1898); Historia de España y de la civilización española (1902, 1930 y 1935), y un trabajo que pensaba publicar en 1934 bajo el título: Tratado de metodología de la historia, pero que a consecuencia de la guerra y de la pérdida de sus materiales no logró publicarlo en ese momento. Texto que esperemos pueda ver la luz algún día, dado que Altamira mencionó que ya no le daba tiempo para rehacer la obra entera a pesar de haber recobrado algunos de sus documentos diez años después. ${ }^{7}$

El curso aquí descrito dio lugar, como se señaló al principio de esta reseña, al libro Proceso histórico de la Historiografía humana, editado por primera vez en 1948 y que tuvo

\footnotetext{
${ }^{4}$ Rafael Altamira, La formación del jurista, estudio preliminar, ed. y notas de Jaime del Arenal Fenochio (México: Escuela Libre de Derecho, 1993), 16.

${ }^{5}$ Rafael Altamira, Proceso histórico de la Historiografía humana (México: El Colegio de México, 1948; 2a. ed., 2011), 14.

${ }^{6}$ Ibíd., 13. Las cursivas en esta y otras citas son de Altamira.

${ }^{7}$ Ibíd., 82.
} 
a bien reeditar El Colegio de México en el marco del Año Internacional Rafael Altamira 2011, para conmemorar los sesenta años del fallecimiento de este intelectual alicantino en el exilio mexicano. En este trabajo don Rafael presenta su técnica historiográfica entendida como:

El concepto que hoy día poseen los historiadores en punto al contenido de la vida de los pueblos que es preciso conocer para estructurar un relato que comprenda, totalmente, las actividades humanas en la fase que llamamos 'civilización', ya que ha desaparecido para todo el mundo aquella dualidad que durante mucho siglos se empeñó en no admitir otra clase de 'historia humana' que la política (es decir, del Estado), dejando aparte todo lo demás que comprende, precisamente, el proceso de cultura y del dinamismo social que ha trabajado siempre por la realización de las necesidades humanas, que no son solamente las del organismo político. ${ }^{8}$

Quizá era muy precipitado por parte del alicantino anunciar el fin de la confrontación entre la historia política y la historia de la civilización. No obstante, esta cita nos viene bien para recordar al lector que Rafael Altamira concebía la historia de la civilización como una historia íntegra y orgánica de los hechos de la humanidad a través del tiempo. Es decir, frente a la concepción de la historia de la civilización como una "historia interna", que comprende sólo a las instituciones sociales y políticas, la vida intelectual y las costumbres, Altamira propone incluir también a la "historia externa", aquella de los hechos propiamente políticos.

El libro está dividido en nueve apartados, además del prólogo y de un apéndice. ${ }^{9}$ El primer apartado nos introduce al plan que desarrolló el profesor Altamira sobre su curso. Del segundo al sexto corresponden a los temas que se programaron para la segunda sección y que, como hemos señalado, constituyó el cuerpo principal del curso. En estos cinco apartados, Altamira recorre la historia de la historiografía principalmente occidental siguiendo el hilo conductor de la discusión entre la historia política y la historia de la civilización, al tiempo que presenta un gran catálogo de autores y sus relatos, resaltando la importancia de los hechos o actos humanos, que "muchas veces son más fuertes que el razonamiento", razón por la cuál - expresa don Rafael - "preferí afianzar la verdad de mis ideas acerca de la Historia por medio de la exposición del proceso que recorrió el concepto de este orden del saber". ${ }^{10}$

Dentro de este bloque de temas, Rafael Altamira expone en un primer momento la concepción política de la Historia durante la Edad Antigua y Media. Destaca sobre todo la historiografía política y religiosa en los pueblos visigodos y la obra de Isidoro de Sevilla; las crónicas y cronicones en los reinos cristianos, su cultura literaria, la poesía castellana del siglo XII, autores como Lucas de Tuy, Rodrigo Jiménez de Rada y Alfonso el Sabio; la historiografía política durante el siglo XV de López de Ayala, Fernández Pérez de Guzmán, Pablo de Santa María y Diego de Varela. Subraya también el libro Prolegómenos de

\footnotetext{
${ }^{8}$ Ibíd., 11.

${ }^{9}$ La segunda edición incorpora los textos de Pilar Altamira: “Altamira en México”; Jaime del Arenal Fenochio: "La historiografía al servicio de la paz”, y Fernando Serrano Migallón: “Ayer y hoy: la idea de la narración histórica en Rafael Altamira. Historia del poder e historia humana. Estos dos últimos también publicados en Boletín editorial-Colegio de México, 152 (julio-agosto 2011).

${ }^{10}$ Rafael Altamira, Proceso histórico de la Historiografía humana, 12.
} 
Abenjaldún, del siglo XIV, que constituye una obra adelantada a su tiempo por "la presencia de una metodología general de la Historia de los pueblos". ${ }^{11}$

En un segundo momento, repasa el surgimiento - dentro y fuera de la historia política - de la "historia civil” en la época del Renacimiento durante los siglos XVI y XVII a través de un grupo selecto de metodólogos e historiadores como Luis Vives, Páez de Castro, Baltasar de Céspedes, Cabrera de Córdoba y los Cronistas de Indias. Estos últimos, según Altamira, aún no habían sido suficientemente estudiados, pero en sus crónicas se podía leer propiamente historiografía de la civilización en "el aspecto indígena y español”, como reflejo del impacto que les había producido en su calidad de testigos tanto la novedad geográfica y antropológica americana, como la nueva realidad política impuesta ahí por la Corona española. ${ }^{12}$ Por otra parte, el alicantino destaca igualmente a otros autores europeos en este largo período de tiempo - incluso algunos que vivieron entre el siglo XVII y el XVIII : Bodín, Le Moyne, Gomberville, Cordemoy, Rollin, Pedro Bayle, Lenglet du Fresnoy, Bacon, Jacopo Aconcio, Stellini, Agustín Marcadi y Patrizzi.

El tercer tema que aborda Altamira tiene que ver con lo que él llama el "nuevo concepto de civilización en los siglos XVIII y XIX”. Un concepto más “democrático de la Historia, que se expresa diciendo que la Historia no es de los príncipes (como se predicó durante muchos siglos), sino de los pueblos”. ${ }^{13}$ En relación con el siglo XVIII, explica los trabajos de metodólogos españoles como el padre Andrés, padre Martín Sarmiento, Jovellanos, Juan Pablo Forner, Masdeu, Capmany, Campomanes y De Osorio; escritores y preceptistas como Gregorio Mayans, Nicolás Antonio, el conde de Lumiares, Juan Francisco Castro, Martínez Salafranca, Sempere y Guarinos, entre otros; los franceses Voltaire y Rousseau; otros como Robertson, abate Velli y abate Millot; arqueólogos como Malingre e historiadores del derecho como Leibniz. Todos ellos, de alguna u otra forma, habían concebido la civilización estudiando por separado las distintas actividades humanas, incluyendo este nuevo concepto en las historias generales.

Sobre el cuarto tema referente al siglo XIX, don Rafael continúa con el debate sobre la concepción más amplia y orgánica de la Historia. Además agrega a su exposición las siguientes cuestiones: la discusión acerca de la crítica de las fuentes; el reforzamiento de la doctrina política como eje de la ciencia histórica; la aparición de la sociología y la confusión terminológica entre civilización y cultura. Todo ello a razón de una referencia comentada de autores y sus obras entre los que destacan Niebuhr, Ranke, Müller, Daunoy, Schlosser, Guizot, Sismondi, Weber, Eugenio de Tapia, Fermín Gonzalo Morón, Oliveira Martins, Macaulay y Buckle.

El quinto tema toca al siglo XX, a los problemas contemporáneos y al debate de la condición científica de la Historia. Para abordarlo Altamira, además de la utilización de la bibliografía, se vale de sus experiencias, por lo que el apartado constituye un documento

\footnotetext{
${ }^{11}$ Ibíd., 25.

12 Ante las pocas colecciones existentes sobre los cronistas de Indias, Altamira propone crear "una colaboración internacional de los Estados americanos donde funcionaron los cronistas: colaboración, en el orden científico y en el auxilio económico, para costear la voluminosa colección general.” Ibíd., 60.

${ }^{13}$ Ibíd., 73.
} 
rico en memorias. Lo divide en dos periodos: 1901-1933 y 1933-1945. Explica que la coyuntura intelectual del inicio del siglo - Congreso Internacional de Ciencias Históricas celebrado en Roma en 1903 y en Berlín en 1908 -, donde se discutió sobre el concepto moderno de la Historia y la tendencia hacia su contenido íntegro, se vio alterada por la Primera Guerra Mundial. Ello derivó en que, a partir de la década de 1920, destacadas personalidades - Lhéritier, Van Tieghem, Tronchou y Febvre - propusieran el estudio común de temas de interés general y de la universalidad de muchos movimientos históricos, con la intención de fomentar la cooperación y dar cuenta de los trabajos científicos, pero, sobre todo, para poner a la historiografía al servicio "del superior interés de la verdad y de la paz" ${ }^{14}$ Campaña a la que se sumaron la Conferencia Internacional de Enseñanza de la Historia - creada en Paris y presidida por Altamira -, algunos profesores franceses y alemanes, y la Comisión Europea de Asuntos Internacionales. Sin embargo, esta laudable iniciativa no pudo detener, a los ojos de don Rafael, la crisis de la historiografía. Por ello, los años de la Segunda Guerra Mundial representaron una pérdida para la cultura y para la investigación histórica. En fechas posteriores a la guerra llegaron a la mesa de los debates otros asuntos que Altamira aborda en la segunda mitad de su libro. Estos asuntos son la discusión sobre el carácter de la cientificidad de la Historia, en relación con la condición literaria de Croce, "que reclama el ingreso de la historiografía en el campo de la literatura", ${ }^{15}$ y con la "teoría condicionada de Aristóteles", en cuanto al tema de las leyes, la generalización, la unidad como sistema, la veracidad de los hechos del pasado, el análisis de los hechos sociales - con el reconocimiento principal de "la posición y estado en que cada momento tuvo el pueblo" $-{ }^{16}$ las contribuciones al conocimiento histórico de la antropología "espiritual” y la psicología, y los nuevos temas a trabajar a consecuencia de la guerra como los efectos de ésta en la milicia, en los refugiados y el estudio de la literatura bélica.

Finalmente, los asuntos que toca Altamira en los últimos apartados del libro están relacionados con una serie de recomendaciones dirigidas a los aprendices del quehacer historiográfico. La primera tiene que ver con el cuidado de los conceptos que se utilizan en la investigación. Una segunda recomendación, a propósito de la relación entre la novela histórica y la historiografía - donde cita los trabajos de Walter Scott y Pérez Galdós -, consiste en que se apliquen las características literarias al género histórico para hacer de la redacción una narración más viva, ya que para don Rafael: "No está obligado el historiador a ser seco para parecer serio. Por el contrario, el triunfo más grande de la historiografía consistiría en poder contar el trozo de proceso humano que cada autor escoge, como el novelista cuenta sus imaginaciones". ${ }^{17}$ Asimismo, en el último apartado de este libro, el profesor Altamira, a través de su obra Estudios sobre las fuentes de conocimiento del derecho indiano: análisis de la Recopilación de las Leyes de Indias de 1680 (1941), instruye cómo aprovechar las fuentes, dado que, a su juicio, a veces pasa inadvertida la riqueza de los datos jurídicos que contienen las leyes coloniales, sobre todo, porque éstas

\footnotetext{
${ }^{14}$ Ibíd., 98.

${ }^{15}$ Ibíd., 151.

${ }^{16}$ Ibíd., 126.

${ }^{17}$ Ibíd., 150.
} 
están llenas de "noticias jurídicas que accidentalmente acompañan a los motivos de cada ley y a su historia, que también existe en muchas de ellas”. ${ }^{18}$

Como comentario final a esta reseña considero que el libro tiene algunas ausencias. En este recorrido histórico de la historiografía que nos presenta Rafael Altamira no encontramos referencias sobre los autores y debates del materialismo histórico ni sobre la escuela de los Annales. Tampoco encontramos comentarios acerca de historiadores y metodólogos latinoamericanos del siglo XIX y principios del XX. Por último, resta expresar que nos congratulamos con que El Colegio de México se haya sumado al homenaje a este humanista español con la reedición de Proceso histórico de la Historiografía humana, que podría considerase todo un clásico.

Juan Manuel Ledezma Martínez

Universidad Autónoma de Madrid (España)

juanmanuel.ledezma@uam.es

Fecha de recepción: 26 de febrero de 2013

Fecha de aceptación: 15 de marzo de 2013

Publicado: 15 de junio de 2013

Para citar: Juan Manuel Ledezma Martínez, "Rafael Altamira, Proceso histórico de la Historiografía humana. México: El Colegio de México, 1948; 2a . ed., 2011), 208 pp.”, Historiografías, 5 (enero-junio, 2013): pp. 122-127,

http://www.unizar.es/historiografias/historiografias/numeros/5/ledezma_res.pdf

${ }^{18}$ Ibíd., 155. 